\title{
Bordetella pertussis in children
} hospitalized with a respiratory infection: clinical characteristics and pathogen detection in household contacts

\author{
Juana del Valle-Mendoza ${ }^{1,2^{*}}$, Wilmer Silva-Caso ${ }^{1,2}$, Miguel Angel Aguilar-Luis ${ }^{1,2,3}$, Cristina del Valle-Vargas ${ }^{3,4}$, \\ Erico Cieza-Mora ${ }^{5}$, Johanna Martins-Luna ${ }^{1}$, Ronald Aquino-Ortega ${ }^{2,3}$, Andrea Silva-Vásquez ${ }^{3}$, \\ Jorge Bazán-Mayra ${ }^{6}$ and Pablo Weilg ${ }^{1 *}$
}

\begin{abstract}
Objective: Describe the prevalence of Bordetella pertussis via PCR in children under 5 years old hospitalized as probable cases of pertussis and report the most common clinical features among them.

Results: A positive PCR result for B. pertussis was observed in 20.5\% of our samples (18/88), one-third of them were from infants between 2 and 3 months old. The most common symptoms were paroxysms of coughing (88.9\%), difficulty breathing (72.2\%), cyanosis (77.8\%) and fever (50\%). The mother was the most common symptomatic carrier (27.8\%), followed by uncles/aunts (22.2\%) among children with pertussis.
\end{abstract}

Keywords: Pertussis, Bordetella pertussis, Whooping cough, PCR, Peru

\section{Introduction}

Pertussis, also known as 'whooping cough', is an acute respiratory tract infection caused by the gram-negative bacteria Bordetella pertussis [1-3]. Worldwide, around 30 million cases of pertussis and 160,000 deaths in children younger than 5 years old are registered every year, $90 \%$ of them occurring in developing countries [4-6].

In the last years, despite a widespread vaccination, the resurgence of $B$. pertussis infections has been observed, primarily affecting low-income countries [7-11]. Despite the pertussis vaccine success, cyclical outbreaks are observed every 2-5 years as they did in the prevaccine era $[12,13]$. Furthermore, the vaccination calendar has left a window of vulnerability for newborns and infants in which high morbidity and mortality rates are observed [14-17]. In addition, in infants younger than 3 months

*Correspondence: juana.delvalle@upc.pe; pablo.weilg@gmail.com ${ }^{1}$ Research and Innovation Centre of the Faculty of Health Sciences, Universidad Peruana de Ciencias Aplicadas, Lima, Peru

Full list of author information is available at the end of the article and neonates the increasing incidence of this infection and the sustained mortality rates have encouraged further investigation about the efficacy and safety of pertussis vaccination for pregnant women as an attempt to reduce the disease burden [18].

In Peru, since 2017 a rapid increase of B. pertussis has been observed and by the first half of the year, the number of cases has doubled compared to the previous year suggesting the possibility of a new outbreak [19]. This study main objective was to describe the prevalence of $B$. pertussis via PCR in children under 5 years old hospitalized as probable cases of pertussis and report the most common clinical features among them.

\section{Main text \\ Materials and methods \\ Patients}

A cross-sectional study was conducted in Cajamarca in coordination with the "Dirección Regional de Salud de Cajamarca, Peru". Cajamarca region is located in 
the Andes Mountain Range and was the second most affected region by $B$. pertussis in 2016 [19].

Children under 5 years old hospitalized as probable cases of pertussis at the Hospital Regional de Cajamarca were consecutively studied from April 2016 to September 2017. Household contacts with similar respiratory complaints were also included in the study and were considered positive after PCR detection of $B$. pertussis.

Cases were defined as probable for pertussis in the absence of a more likely diagnosis of cough illness with one of the following symptoms: Paroxysms of coughing or inspiratory "whoop" or posttussive vomiting or apnea as per CDC case definition recommendations [20].

This study was approved by the Research Ethics Board of the Hospital Docente Regional de Cajamarca, Peru. A written informed consent was signed by parents or children caregivers before enrollment. Household contacts also signed a written informed consent before enrollment.

\section{Samples}

Nasopharyngeal samples were obtained inserted one swab into each nostril parallel to the palate (calcium alginate swab, USA) and submerged into transport solution (phosphate buffered saline).

\section{DNA extraction}

DNA was extracted from a volume of $200 \mu \mathrm{l}$ of each samples using a commercial kit (High Pure Template Preparation Kit, Roche Applied Science, Germany) according to the manufacturer's instructions.

\section{Real-time PCR assay detection Bordetella pertussis with the TaqMan probe}

PCR was performed using a BHQ quencher probe at 125 and $250 \mathrm{nM}$ of primers in a final volume of $20 \mu \mathrm{l}$. Five microliters of the extracted DNA were combined with $15 \mu \mathrm{l}$ of the master mix. PCR conditions for $B$. pertussis were $95{ }^{\circ} \mathrm{C}$ for $10 \mathrm{~s}, 60$ cycles of $5 \mathrm{~s}$ at $95^{\circ} \mathrm{C}, 5 \mathrm{~s}$ at $57{ }^{\circ} \mathrm{C}$ and $30 \mathrm{~s}$ at $72{ }^{\circ} \mathrm{C}$. All cycles were performed in Light Cycler ${ }^{\circledR} 2.0$ (Roche Diagnostic, Deutschland-Mannheim, Germany). The primers and the probe used were described by Kosters et al. [21].

\section{Statistical analysis}

Quantitative variables were described as frequencies and percentages for each group using the GraphPad Prism3 statistical (Graph Pad Sofware Inc., San Diego, USA).

\section{Results}

A total of 88 children under 5 years old hospitalized as probable cases of pertussis were prospectively studied from April 2016 to September 2017. In our study population, more than $70 \%$ of patients were infants under 3 months old, with infants between 29 days to 2 months old being the most predominant age group in $31.8 \%$ of patients. No significant difference between gender was observed among our patients as $53.4 \%$ were male vs 46.6\% females (Table 1 ).

A positive PCR result for $B$. pertussis was observed in $20.5 \%$ of our samples $(18 / 88)$, one-third of them were from infants between 2 and 3 months old followed by three positive cases on infants between 29 to 2 months old and three cases in children between 1 and 5 years old. Most of our patients with a positive sample were male infants in $72.2 \%$ of cases (Table 1 ).

Our patients were hospitalized as probable cases of 'whooping cough' and the most common presenting symptoms were paroxysms of coughing (76.1\%), difficulty breathing (75\%), cyanosis (67\%) and fever (52.3\%). The same symptoms were also observed among patients with positive samples for $B$. pertussis in which paroxysms of coughing (88.9\%), difficulty breathing (72.2\%), cyanosis $(77.8 \%)$ and fever $(50 \%)$ were the most frequent complaints. Furthermore, clinical symptoms were compared by age groups showing that paroxysmal coughing was the most common symptom across all ages, except in neonates were cyanosis was the most common presentation. Complications during hospitalization were also registered, pneumonia was the most frequent outcome

Table 1 Demographics of patients with whooping cough syndrome and Bordetella pertussis

\begin{tabular}{lcl}
\hline Characteristics & $\begin{array}{l}\text { Total of patients } \\
\mathbf{n = 8 8}(\%)\end{array}$ & $\begin{array}{l}\text { Patients positive } \\
\text { for B. pertussis } \mathbf{n = 1 8} \\
(\%)\end{array}$ \\
\hline Age & $13(14.8)$ & $2(11.1)$ \\
$<28$ days & $28(31.8)$ & $3(16.7)$ \\
29 days-<2 months & $21(23.9)$ & $6(33.3)$ \\
$2-<3$ months & $10(11.4)$ & $2(11.1)$ \\
3-5 months & $6(6.8)$ & $2(11.1)$ \\
6-11 months & $6(6.8)$ & $3(16.7)$ \\
1-5 years & & \\
Gender & $47(53.4)$ & $13(72.2)$ \\
Male & $41(46.6)$ & $5(27.8)$ \\
Female & & \\
Household contacts & $14(15.9)$ & $5(27.8)$ \\
Mother & $7(8)$ & $3(16.7)$ \\
Father & $14(15.9)$ & $3(16.7)$ \\
Siblings <7 years old & $7(8)$ & $2(11.1)$ \\
Siblings 7-10 years old & $7(2.3)$ & $1(5.6)$ \\
Siblings > 10 years old & $2(22.2)$ \\
Uncles/aunts & $6(6.8)$ & $3(16.7)$ \\
Others & $11(12.5)$ & \\
\hline
\end{tabular}


in $33 \%$ of our study population and $38.9 \%$ of our patients with B. pertussis (Table 2). In addition, 83\% (15/18) of our patients with $B$. pertussis received antibiotic on day 1 of hospitalization, the same day we enrolled them but before we sampled and reported our results.

High leukocyte and lymphocyte count were assessed in our patients. We observed that both leukocytosis and lymphocytosis were present in four cases with $B$. pertussis. On the other hand, leukocytosis and lymphocytosis were also observed in three and four patients with negative results for $B$. pertussis respectively (Additional file 1: Table S1).

From our patients with a positive result for $B$. pertussis, most cases older than 2 months old didn't receive any vaccination $76.9 \%(10 / 13)$, one patient had the incomplete vaccination and only one patient with a positive sample for $B$. pertussis received the two vaccine doses (Additional file 1: Table S2).

Household contacts who presented with respiratory symptoms were also evaluated for the presence of $B$. pertussis. We found that mothers and siblings under 7 years old were the most common family members with positive samples for $B$. pertussis in our population. This predominance was more evident among patients with $B$. pertussis in which $27.8 \%(5 / 18)$ of their mother were also positive for the bacteria (Table 1).

We enrolled patients with a clinical presentation compatible with whooping cough through the whole study period. However, most of our patients with positive samples for B. pertussis were observed during 2017, being January and June the months with the higher case-rate distribution (Fig. 1).

\section{Discussion}

Latin America has experienced a resurgence of B. pertussis infections with high morbidity and mortality rates among infants younger than 6 months old, who represent up to $75 \%$ of pertussis cases [5, 22-28].

In our study, a total of 18 cases (20.5\%) had positive samples for B. pertussis, being $70 \%$ of them infants under 3 months old. This proportion of positive samples is slightly lower than a previous study we conducted in 2015 , where $38.4 \%$ of probable cases for pertussis were also positive for the bacteria [27]. However, these variations are expected as the clinical features have shown to be insufficient to establish a diagnosis and it is estimated that without PCR testing, the overall percentage of missed cases would range from 9 to $26 \%$ per year in infants under 6-month-old [29].

Even though pertussis clinical presentation tends to be unspecific, there are some clinical features that seem to be more common in different age groups [14, 30]. In our population, we observed that difficulty breathing and cyanosis were present in most of our patients between 29 days to 3 months old; however, we were surprised that paroxysmal coughing was also a common symptom in this age group. Additionally, it also has been reported that post-tussive vomiting is common at all ages [14]; in

Table 2 Clinical symptoms among patients with whooping cough syndrome and Bordetella pertussis

\begin{tabular}{|c|c|c|c|c|c|c|}
\hline \multirow[t]{2}{*}{ Clinical symptoms } & \multirow{2}{*}{$\begin{array}{l}\text { Total of patients } \\
n=88(\%)\end{array}$} & \multicolumn{5}{|c|}{ Patients positive for $B$. pertussis $n=18(\%)$} \\
\hline & & $\begin{array}{l}<28 \text { days } \\
n=2\end{array}$ & $\begin{array}{l}29 \text { days }-<3 \text { months } \\
n=9\end{array}$ & $\begin{array}{l}3-5 \text { months } \\
n=2\end{array}$ & $\begin{array}{l}6-11 \text { months } \\
n=2\end{array}$ & $\begin{array}{l}1-5 \text { years } \\
n=3\end{array}$ \\
\hline Paroxysmal cough & $67(76.1)$ & $1(5.6)$ & $7(38.9)$ & $2(11.1)$ & $2(11.1)$ & $3(16.7)$ \\
\hline Difficulty breathing & $66(75)$ & $1(5.6)$ & $6(33.3)$ & $1(5.6)$ & $2(11.1)$ & $3(16.7)$ \\
\hline Cyanosis & $59(67)$ & $2(11.1)$ & $7(38.9)$ & $1(5.6)$ & $2(11.1)$ & $2(11.1)$ \\
\hline Fever & $46(52.3)$ & $1(5.6)$ & $5(27.8)$ & $0(0)$ & $1(5.6)$ & $2(11.1)$ \\
\hline Posttussive emesis & $34(38.6)$ & $1(5.6)$ & $4(22.2)$ & $0(0)$ & $1(5.6)$ & $2(11.1)$ \\
\hline Breastfeeding difficulties & $32(36.4)$ & $1(5.6)$ & $3(16.7)$ & $1(5.6)$ & $0(0)$ & $0(0)$ \\
\hline Ruddiness & $21(23.9)$ & $1(5.6)$ & $1(5.6)$ & $1(5.6)$ & $1(5.6)$ & $1(5.6)$ \\
\hline Stridor & $16(18.2)$ & $0(0)$ & $1(5.6)$ & $1(5.6)$ & $2(11.1)$ & $1(5.6)$ \\
\hline Diarrhea & $15(17)$ & $0(0)$ & $3(16.7)$ & $0(0)$ & $0(0)$ & $1(5.6)$ \\
\hline Apnea & $9(10.2)$ & $0(0)$ & $2(11.1)$ & $0(0)$ & $0(0)$ & $0(0)$ \\
\hline \multicolumn{7}{|l|}{ Complications } \\
\hline Pneumonia & $29(33)$ & $1(5.6)$ & $5(27.8)$ & $0(0)$ & $0(0)$ & 1 (5.6) \\
\hline $\begin{array}{l}\text { Acute bronquial obstruc- } \\
\text { tive syndrome }\end{array}$ & 18 (20.5) & $0(0)$ & $0(0)$ & $0(0)$ & $1(5.6)$ & $1(5.6)$ \\
\hline Atelectasis & $10(11.4)$ & $0(0)$ & $2(11.1)$ & $0(0)$ & $1(5.6)$ & $1(5.6)$ \\
\hline Convulsions & $4(4.5)$ & $0(0)$ & $2(11.1)$ & $0(0)$ & $0(0)$ & $0(0)$ \\
\hline Umbilical hernia & $1(1.1)$ & $1(5.6)$ & $0(0)$ & $0(0)$ & $0(0)$ & $0(0)$ \\
\hline
\end{tabular}




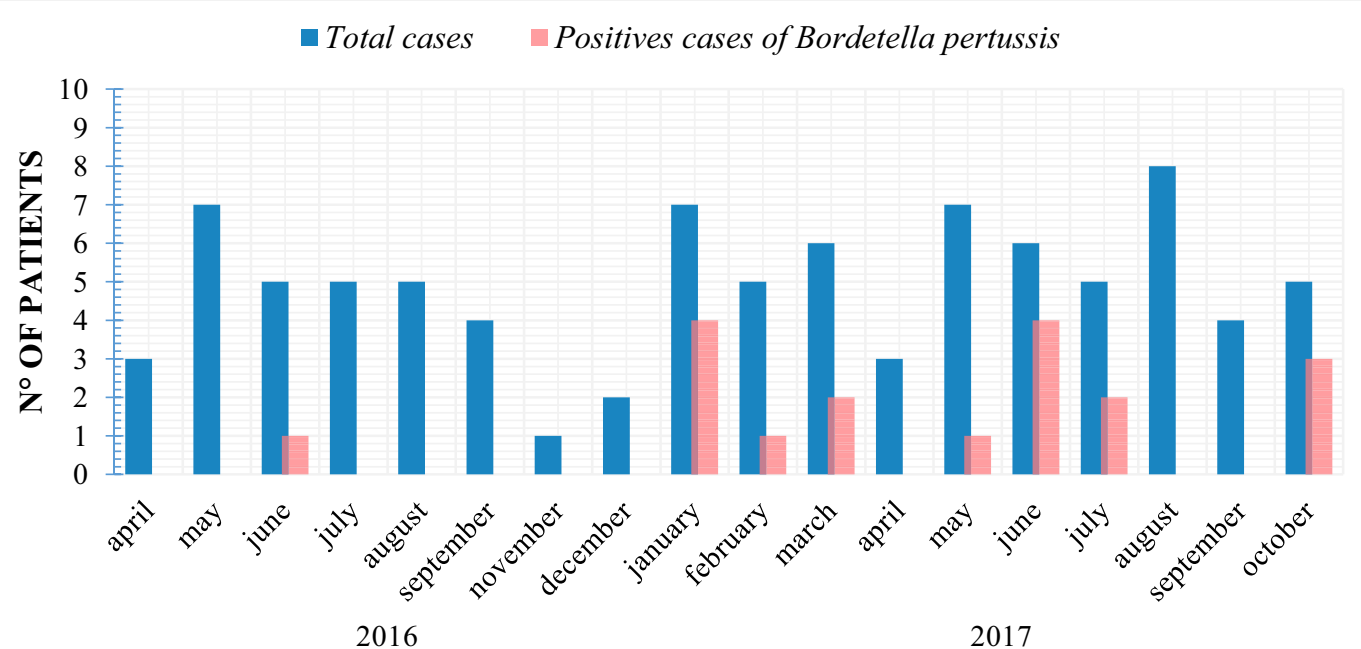

TIME (MONTH)

Fig. 1 Seasonal distribution among patients with whooping cough syndrome and B. pertussis

our series, it was present in $44.4 \%(8 / 18)$ of patients with B. pertussis.

It has been demonstrated that a whooping cough alone is not enough to start antibiotics immediately, especially in infants younger than 4 months [5]. However, in rural areas where laboratory resources are limited physician usually give macrolides when there is high suspicious of pertussis. In our population, $17 \%(15 / 88)$ of patients received antibiotics on day 1 of hospitalization before we took samples. In addition, $83 \%(15 / 18)$ of patients with $B$. pertussis were covered before we report their results as positive, and the other three cases were started on antibiotics the same day we sent our results.

One study in Mexican infant showed that $59 \%$ of patients with pertussis had leukocytosis and $64.4 \%$ presented lymphocytosis, with a mean age of 87.1 days old [31]. In our study, we found that leukocytosis and lymphocytosis were each observed only in 4 (22.2\%) pertussis cases. However, these findings were not exclusive among patients with $B$. pertussis, as we found three patients with leukocytosis and four with lymphocytosis in the group of patients with negative samples.

Bordetella pertussis is a highly contagious disease acquired through direct contact or inhalation and the source of infection is usually the mother has been identified as the most common source in up to $63 \%$ of cases, followed by fathers, siblings and other family members $[11,17,31]$. In our study, among children with B. pertussis, we found that mothers were the most common symptomatic carriers in $27.8 \%(5 / 18)$ of patients, followed by uncles or aunts in six cases. Notably, we also found nine mothers with $B$. pertussis among infants with negative samples of the bacteria demonstrating the presence of carriers even in patients without the disease.

Evidence suggests that the households contacts transmission occurs due to the limited immunity to $B$. pertussis infection whether acquired naturally or by immunization [32]. In adult carriers, who usually do not receive booster protection, the levels of protective antibodies almost negligible with more than $50 \%$ of them lost in the first 6 years after vaccination [33]. On the other hand, contacts between 0 and 18 years old, primarily represented by the patients' siblings, are usually carriers without vaccination or incomplete schedules who did not receive chemoprophylaxis [34].

The most recognized strategy is the maternal pertussis immunization supported by the World Health Organization (WHO) which has been found to be highly effective at preventing severe disease in infants [34-37]. However, the effectiveness of pertussis immunization in preventing transmission in other household contacts is mostly unknown [33, 34]. Nevertheless, it is recommended that all contacts who have an incomplete immunization should be vaccinated in addition to receiving chemoprophylaxis. In addition, adolescents and adults, especially those in close contact with children, may benefit from a booster dose of the acellular vaccine. Although, this immunity will wane considerably fast having no impact in a distant future [34].

We analyzed pertussis vaccination status in our population. Not surprisingly, we observed that $76.9 \%(10 / 13)$ our patients older than 2 months old with $B$. pertussis didn't receive any vaccination. Thus, indicating that children with incomplete vaccination are prone to be 
infected by the bacteria as we found in two cases. Finally, infants too young to receive the pertussis vaccine represented $27.8 \%$ (5/18) of our patients with $B$. pertussis, demonstrating once again the vulnerability window of our immunization calendar.

\section{Conclusions}

Bordetella pertussis is an important cause of respiratory tract infection in children under 5 years of age, primarily affecting infants under 6 months old in whom the diagnosis is not always suspected. The vaccination schedule leaves a window of vulnerability for $B$. pertussis infection among infants under 2 months old. In rural areas of Peru, limited laboratory resources may contribute to the underdiagnosis of the disease and an increased use of macrolides upon clinical criteria. In our study, mothers were the most common symptomatic carrier in patients with and without pertussis.

\section{Limitations}

The present study had one important limitations. We designed the study for the detection of $B$. pertussis we cannot exclude the presence of other etiologies that may be responsible for the patients' clinical presentation.

\section{Additional file}

Additional file 1: Table S1. Leukocytosis and lymphocytosis in children with whooping cough syndrome. Table $\mathbf{S 2}$. The following normal values were used as a reference to determine high counts of white blood cells and lymphocytes in each age group.

\section{Abbreviations \\ PCR: polymerase chain reaction; DNA: deoxyribonucleic acid; bp: base pairs; $B$. pertussis: Bordetella pertussis.}

\section{Authors' contributions}

JdVM conceived the study; JdVM, PW, and WS designed the study protocol; MAAL, RAO, CdV, and JML performed real-time PCR, analysis and interpretation of these data. JBM, EC, WS and AS responsible for the collection of samples and for completing the clinical information of the epidemiological filled. JdVM, $\mathrm{CdV}$, and PW drafted the manuscript; JdVM and PW critically revised the manuscript for intellectual content. All authors critically revised the manuscript for intellectual content. All authors read and approved the final manuscript.

\section{Author details}

${ }^{1}$ Research and Innovation Centre of the Faculty of Health Sciences, Universidad Peruana de Ciencias Aplicadas, Lima, Peru. ${ }^{2}$ Laboratorio de Biología Molecular, Instituto de Investigación Nutricional, Lima, Peru. ${ }^{3}$ Instituto de Investigación de Enfermedades Infecciosas, Lima, Peru. ${ }^{4}$ Facultad de Medicina, Univesidad de Barcelona, Barcelona, Spain. ${ }^{5}$ Servicio de Pediatría, Hospital Docente Regional de Salud de Cajamarca, Cajamarca, Peru. ${ }^{6}$ Laboratorio de Referencia, Dirección Regional de Salud de Cajamarca (DIRESA), Cajamarca, Peru.

\section{Acknowledgements}

Pediatric health personnel from all Hospitals participating in the study.

\section{Competing interests}

The authors declare that they have no competing interests.

\section{Availability of data and materials}

Abstraction format used in the study and dataset are available and accessible from the corresponding author upon request. Data available in the link: https ://figshare.com/articles/Dataset_bordetella_2018/5776713.

\section{Consent to publish}

Not applicable.

\section{Ethics approval and consent to participate}

This study has been approved by two independent Ethics Committees from Hospital Docente Regional de Cajamarca. All samples were analyzed after a written informed consent was signed by parents or children's caregivers.

\section{Funding}

This work was supported by fourth research incentive of the Universidad Peruana de Ciencias Aplicadas (UPC), Lima-Peru.

\section{Publisher's Note}

Springer Nature remains neutral with regard to jurisdictional claims in published maps and institutional affiliations.

Received: 16 February 2018 Accepted: 7 May 2018

Published online: 18 May 2018

\section{References}

1. Mattoo S, Cherry J. Molecular pathogenesis, epidemiology, and clinical manifestations of respiratory infections due to Bordetella pertussis and other Bordetella subspecies. Clin Microbiol Rev. 2005;18(2):326.

2. Carbonetti H. Contribution of pertussis toxin to the pathogenesis of pertussis disease. Pathog Dis. 2015;73(8):ftv073.

3. Warfel J, Beren J, Merkel T. Airborne transmission of Bordetella pertussis. J Infect Dis. 2012;206(6):902 (Epub 2012 Jul 17).

4. Center for Disease Control and Prevention (CDC). Pertussis in other countries. Atlanta. https://www.cdc.gov/pertussis/countries/index.html. Accessed 29 Nov 2017; Cited 30 Nov 2017.

5. Villegas D, Echandia-Villegas C, Echandia C. Afebrile pneumonia (whooping cough) syndrome in infants at Hospital Universitario del Valle, Cali, 2001-2007. Colomb Med (Cali). 2012;43(2):114-8.

6. Yeung K, Duclos P, Nelson E, Hutubessy R. An update of the global burden of pertussis in children younger than 5 years: a modeling study. Lancet Infect Dis. 2017;17(9):974-80.

7. Bamberger ES, Srugo I. What's new in pertussis? Eur J Pediatr. 2008;167:133-9.

8. Nicolai A, Nenna R, Stefanelli P, Carannante A, Schivariello C, Pierangeli A, et al. Bordetella pertussis in infants hospitalized for acute respiratory symptoms remains a concern. BMC Infect Dis. 2013;8(13):526.

9. Mooi FR, van Oirschot H, Heuvelman K, van der Heide HG, Gaastra W, Willems RJ. Polymorphism in the Bordetella pertussis virulence factors P.69/ Pertactin and pertussis toxin in the Netherlands: temporal trends and evidence for vaccine-driven evolution. Infect Immun. 1998;66:670-5.

10. Suárez-Idueta L, Herbas-Rocha I, Gómez-Altamirano CM. Tosferina, un problema vigente de salud pública en México. Planteamiento de la necesidad para introducir una nueva vacuna. Bol Med Hosp Infant Mex. 2012;69:314-20.

11. Huang H, Gao Z, Liu Y, Wang L, Liu Y, Zhang Y. Epidemiological characteristics and risk factors of the pertussis in infants $<12$ months of age in tianjin, China. Biomed Environ Sci. 2017;30(7):545-8.

12. Mink C, Cherry J, Christenson P, Lewis K, Pineda E, Shlian D, et al. A search for Bordetella pertussis infection in university students. Clin Infect Dis. 1992;14(2):464-71.

13. Cherry J. The epidemiology of pertussis: a comparison of the epidemiology of the disease pertussis with the epidemiology of Bordetella pertussis infection. Pediatrics. 2005;115:1422.

14. Berti E, Venturini E, Galli L, de Martino M, Chiappini E. Management and prevention of pertussis infection in neonates. Expert Rev Anti Infect Ther. 2014;12(12):1515-31.

15. Berti E, Chiappini E, Orlandini E, et al. Pertussis is still common in a highly vaccinated infant population. Acta Paediatr. 2014;103:846-9. 
16. Chiappini E, Stival A, Galli L, et al. Pertussis re-emergence in the postvaccination era. BMC Infect Dis. 2013;13:151.

17. Huang L, Ho M, Chen C. A neonate with Bordetella pertussis pneumonia presenting with cough and cyanosis. J Pediatr Resp Dis. 2013;9:87-90.

18. Furuta M, Sin J, Ng E, Wang K. Efficacy and safety of pertussis vaccination for pregnant women - a systematic review of randomized controlled trials and observational studies. BMC Pregnancy Childbirth. 2017;17(1):390

19. Red Nacional de Epidemiologia (RENACE). Sala de Situación de Salud Perú: Tos Ferina. Lima, Perú. Dirección General de Epidemiología (DGE). http://www.dge.gob.pe/portal/docs/vigilancia/sala/2017/salaSE22.pdf. Accessed 29 Nov 2017; Cited 30 Nov 2017.

20. Center for Disease Control and Prevention (CDC). Pertussis (Whooping Cough) surveillance and reporting. Atlanta. https://www.cdc.gov/pertu ssis/surv-reporting.html. Accessed 29 Nov 2017; Cited 30 Nov 2017.

21. Kosters K, Riffelmann M, von König CHW. Evaluation of a real-time PCR assay for detection of Bordetella pertussis and B. parapertussis in clinical samples. J Med Microbiol. 2001;50:436-40.

22. Bosch J, Fernandez H, Polak F, Musante G, Libster R, Rocca M. Seroprevalence of Bordetella pertussis among vaccinated and unvaccinated pregnant women and newborn infants in a university hospital of Buenos Aires. Arch Argent Pediatr. 2017;115(4):311-5.

23. Giayetto V, Blanco S, Mangeaud A, Barbas M, Cudola A, Gallego S. Features of Bordetella pertussis, Bordetella spp. infection and whooping cough in Córdoba province, Argentina. Rev Chilena Infectol. 2017;34(2):108-15

\section{(Article in Spanish).}

24. Lavayen S, Zotta C, Cepeda M, Lara C, Rearte A, Regueira M. Infection by Bordetella pertussis and Bordetella parapertussis in cases of suspected whooping cough (2011-2015) in Mar del Plata, Argentina. Rev Peru Med Exp Salud Publica. 2017:34(1):85-92 (Article in Spanish)

25. Phadke V, McCracken J, Kriss J, Lopez M, Lindblade K, Bryan J, et al. Clinical characteristics of hospitalized infants with laboratory-confirmed pertussis in Guatemala. J Pediatr Infect Dis Soc. 2017. https://doi.org/10.1093/jpids/ pix081.

26. Castillo M, Bada C, Del Aguila O, Petrozzi-Helasvuo V, Casabona-Ore V, Reyes I, et al. Detection of Bordetella pertussis using a PCR test in infants younger than one year old hospitalized with whooping cough in five Peruvian hospitals. Int J Infect Dis. 2015;41:36-41.

27. Del Valle-Mendoza J, Casabona-Ore V, Petrozzi-Helasvuo V, Cornejo-Tapia A, Weilg P, Pons M, et al. Bordetella pertussis diagnosis in children under five years of age in the Regional Hospital of Cajamarca, Northern Peru. J Infect Dev Ctries. 2015;9(11):1180-5.

28. Pavic-Espinoza I, Bendezu-Medina S, Herrera-Alzamora A, Weilg P, Pons $\mathrm{M}$, Aguilar-Luis M, et al. High prevalence of Bordetella pertussis in children under 5 years old hospitalized with acute respiratory infections in Lima, Peru. BMC Infect Dis. 2015;2(15):554.

29. Fry NK, Duncan J, Wagner K, et al. Role of PCR in the diagnosis of pertussis infection in infants: 5 years' experience of provision of a same-day real-time PCR service in England and Wales from 2002 to 2007. J Med Microbiol. 2009;58:1023-9.

30. Snapp B, Fischetti D. Bordetella pertussis infection in infants: a reemerging disease. Adv Neonatal Care. 2013;13(2):103-7.

31. Aquino-Andrade A, Martinez-Leyva G, Merida-Vieyra J, Saltigeral P, Lara A, Dominguez W. Real-time polymerase chain reaction-based detection of Bordetella pertussis in Mexican infants and their contacts: a 3-year multicenter study. J Pediatr. 2017;188(217-223):e1.

32. Wirsing von Koning C, Postels-Multani S, Bogaerts H, Bock H, Laukamp S, Kiederle $\mathrm{S}$, et al. Factors influencing the spread of pertussis in households. Eur J Pediatr. 1998;157(5):391-4.

33. Bisgard K, Pascual F, Ehresmann K, Miller C, Cianfrini C, Jennings C, et al. Infant pertussis: who was the source? Pediatr Infect Dis J. 2004;23(11):985-9.

34. Godoy P, Garcia-Cenoz M, Toledo D, Carmona G, Cayla J, Alseda M, et al. Factors influencing the spread of pertussis in households: a prospective study, Catalonia and Navarre, Spain, 2012 to 2013. Euro Surveillance. 2016;21(45):30393.

35. World Health Organization (WHO). Summary of the Pertussis vaccines: WHO position paper. Geneva. http://www.who.int/immunization/docum ents/pertussis_pp_2015_summary.pdf. Accessed 7 Apr 2018; Cited 9 Apr 2018.

36. Saul N, Wang K, Bag S, Baldwin H, Alexander K, Chandra M, et al. Effectiveness of maternal pertussis vaccination in preventing infection and disease in infants: the NSW Public Health Network case-control study. Vaccine. 2018;36(14):1887-92.

37. Issacs D. Maternal pertussis immunisation. J Paediatr Child Health. 2018:54(3):334.

Ready to submit your research? Choose BMC and benefit from:

- fast, convenient online submission

- thorough peer review by experienced researchers in your field

- rapid publication on acceptance

- support for research data, including large and complex data types

- gold Open Access which fosters wider collaboration and increased citations

- maximum visibility for your research: over $100 \mathrm{M}$ website views per year

At BMC, research is always in progress.

Learn more biomedcentral.com/submissions 